Relations industrielles

Industrial Relations

\title{
La France et le management, par Roger Priouret, Denoël, Paris,
} 1968, 407 pages

\section{Pierre Brien}

Volume 24, numéro 1, 1969

URI : https://id.erudit.org/iderudit/028008ar

DOI : https://doi.org/10.7202/028008ar

Aller au sommaire du numéro

\section{Éditeur(s)}

Département des relations industrielles de l'Université Laval

\section{ISSN}

0034-379X (imprimé)

1703-8138 (numérique)

Découvrir la revue

Citer ce compte rendu

Brien, P. (1969). Compte rendu de [La France et le management, par Roger Priouret, Denoël, Paris, 1968, 407 pages]. Relations industrielles / Industrial Relations, 24(1), 226-226. https://doi.org/10.7202/028008ar

Tous droits réservés @ Département des relations industrielles de l'Université Laval, 1969
Ce document est protégé par la loi sur le droit d'auteur. L'utilisation des services d’Érudit (y compris la reproduction) est assujettie à sa politique d'utilisation que vous pouvez consulter en ligne.

https://apropos.erudit.org/fr/usagers/politique-dutilisation/ 
quoi elle est la bonne et pour se faire utilise les réponses fausses que le lecteur aurait pu choisir.

Ce livre s'adresse surtout aux praticiens et c'est là son intérêt.

\section{Bernard SOLASSE}

La France et le management, par Roger Priouret, Denoël, Paris, 1968, 407 pages.

Après le Défi Américain de Servan Schreiber, Priouret expose les problèmes de son pays mais fait appel à des personnalités connues pour leurs succès administratifs afin de donner une image plus dynamique de la France.

Dans une première partie, Priouret rappelle la situation patronale française et le rôle économique du gouvernement comme une source du malaise actuel. De plus, il souligne qu'il ne faut pas engager des batailles perdues d'avance. Il faudrait aussi effectuer une mise sous tension rationnelle de l'ensemble des éléments qui composent une entreprise. Enfin, il rappelle qu'il conviendrait de réhabiliter la notion de profit.

La seconde partie repose sur de précieux témoignages qui reposent sur les sujets suivants: l'autofinancement, la participation aux profits, le recrutement et le traitement des cadres, la décentralisation de l'entreprise, la diversification des produits, et l'évolution générale des entreprises qui sont sous la gestion des interviewés.

\section{Pierre BRIEN}

\section{Unemployment, Money Wage Rates,} and Inflation, by George L. Perry; The M.I.T. Press, Boston, 1966, pp. $\mathrm{XV}, 143$.

Le livre de Perry utilise les modèles développés par Phillips et Lipsey pour analyser les relations salaire, emploi et prix aux Etats-Unis. Il s'agit d'une des études les plus importantes dans ce domaine, jamais entreprises aux EtatsUnis. L'auteur fait d'abord un rappel des principales études déjà faites sur les équations de salaire; puis il bâtit son propre modèle d'analyse de régression mul- tiple où en plus des traditionnelles variables, salaire, chômage et prix, il introduit le niveau et les variations de profits parmi les variables inclépendantes. Les observations portent sur des données trimestrielles d'après-guerre. De plus, comme l'auteur construit ses variables sur la base des variations annuelles ramenées en pourcentage, il suit que chaque observation retenue contient trois trimestres de l'observation précédente. S'il existe un certain degré de corrélation entre les trimestres et les variations de salaires, cette méthode a pour effet d'introduire de l'autocorrélation des erreurs résiduelles. L'auteur consacre plusieurs pages pour traiter de cette question.

Les périodes couvertes par l'étude du professeur Perry portent principalement sur l'après-guerre, néanmoins certaines de ses estimations remontent à 1920 . Les résultats qu'il obtient pour les trimestres compris entre 1948 et 1960 se ramènent à l'équation suivante pour l'ensemble de l'industrie de transformation aux EtatsUnis :

$$
\begin{aligned}
& \mathrm{W}_{\mathrm{t}}=-4.313+0.357 \mathrm{C}_{\mathrm{t}-1}+14.711 \mathrm{U}_{\mathrm{t}-1} \\
& \text { (0.054) } \\
& +0.424 R_{t-1}+0.796 \Delta R \text {. } \\
& \text { (0.068) } \\
& \mathbf{R}^{2}=.870
\end{aligned}
$$

où $\mathrm{W}_{\mathrm{t}}$ désigne les variations annuelles de salaire, $C$ les variations annuelles de l'indice des prix au consornmateur, et U le taux de chômage, R, le taux de profit.

A partir de cette équation, le professeur Perry construit plusieurs jeux de "trade-off". Par exemple, substituant dans l'équation des salaires la relation $\mathrm{C}=\mathrm{W}-\mathrm{P}$ où $\mathrm{P}$ est le taux de croissance de la productivité, il obtient les taux de chômage correspondant à certains taux donnés de productivité et de chômage ainsi qu'aux variations de salaires. En général les niveaux de chômage qu'il obtient en solutionnant les relations de "trade-off" sont relativement élevés. Ainsi avec un taux annuel de la croissance de la productivité de $3 \%$, la stabilité des prix est associée à un taux de chômage de $6 \%$. Dans ses analyses de "trade-off", Perry fait l'hypothèse que l'élasticité de substitution entre le travail et le capi- 